\title{
Genetic Dissection of a Precocious Phenotype in Male Tiger Pufferfish (Takifugu rubripes) using Genotyping by Random Amplicon Sequencing, Direct (GRAS-Di)
}

\author{
Sota Yoshikawa ${ }^{1,2} \cdot$ Masaomi Hamasaki $^{1} \cdot$ Kazushi Kadomura $^{1} \cdot$ Toshiyuki Yamada $^{1} \cdot$ Hisashi Chuda $^{3}$. \\ Kiyoshi Kikuchi ${ }^{2}$ (D) Sho Hosoya ${ }^{2}$ (1)
}

Received: 4 September 2020 / Accepted: 21 December 2020 / Published online: 18 February 2021

(c) The Author(s) 2021

\begin{abstract}
The novel non-targeted PCR-based genotyping system, namely Genotyping by Random Amplicon Sequencing, Direct (GRAS-Di), is characterized by the simplicity in library construction and robustness against DNA degradation and is expected to facilitate advancements in genetics, in both basic and applied sciences. In this study, we tested the utility of GRAS-Di for genetic analysis in a cultured population of the tiger pufferfish Takifugu rubripes. The genetic analyses included family structure analysis, genetic map construction, and quantitative trait locus (QTL) analysis for the male precocious phenotype using a population consisting of four full-sib families derived from a genetically precocious line. An average of 4.7 million raw reads were obtained from 198 fish. Trimmed reads were mapped onto a Fugu reference genome for genotyping, and 21,938 putative single-nucleotide polymorphisms (SNPs) were obtained. These $22 \mathrm{~K} \mathrm{SNPs} \mathrm{accurately} \mathrm{resolved} \mathrm{the} \mathrm{sibship}$ and parent-offspring pairs. A fine-scale linkage map (total size: $1,949 \mathrm{cM}$; average interval: $1.75 \mathrm{cM}$ ) was constructed from 1,423 effective SNPs, for which the allele inheritance patterns were known. QTL analysis detected a significant locus for testes weight on Chr_14 and three suggestive loci on Chr_1, Chr_8, and Chr_19. The significant QTL was shared by body length and body weight. The effect of each QTL was small (phenotypic variation explained, PVE: 3.1-5.9\%), suggesting that the precociousness seen in the cultured pufferfish is polygenic. Taken together, these results indicate that GRAS-Di is a practical genotyping tool for aquaculture species and applicable for molecular breeding programs, such as marker-assisted selection and genomic selection.
\end{abstract}

Keywords GRAS-Di · Family structure analysis · Linkage map · Quantitative trait locus · Tiger pufferfish · Precociousness

\begin{tabular}{|c|c|c|c|}
\hline \multicolumn{2}{|c|}{ Abbreviations } & GF & Grandfather \\
\hline BW & Body weight & GM & Grandmother \\
\hline \multirow{2}{*}{$\begin{array}{l}\mathrm{CI} \\
\mathrm{E} 2\end{array}$} & Credible interval & GRAS-Di & Genotyping by random amplicon sequencing, \\
\hline & Estradiol-17 $\beta$ & & direct \\
\hline \multirow{2}{*}{$\mathrm{F}_{1}$} & First generation & GS & Genomic selection \\
\hline & Second generation & GSI & Gonadosomatic index \\
\hline $\begin{array}{l}\mathrm{F}_{2} \\
\mathrm{FA}\end{array}$ & Father 1 & LOD & Log of odds \\
\hline \multirow{2}{*}{$\begin{array}{l}\text { FA2 } \\
\text { GBS }\end{array}$} & Father 2 & MO1 & Mother 1 \\
\hline & Genotyping-by-sequencing & $\mathrm{MO} 2$ & Mother 2 \\
\hline GBS & & NPIF & Nagasaki Prefectural Institute of Fisheries \\
\hline \multirow{3}{*}{$\triangle$} & \multirow{3}{*}{$\begin{array}{l}\text { Sho Hosoya } \\
\text { ahosoya@mail.ecc.u-tokyo.ac.jp }\end{array}$} & PIT & Passive integrated transponder \\
\hline & & PVE & Phenotypic variation explained \\
\hline & & QTL & Quantitative trait locus \\
\hline 1 & Nagasaki Prefectural Institute of Fisheries, Nagasaki, Japan & SL & Standard length \\
\hline \multirow[t]{2}{*}{2} & Fisheries Laboratory, Graduate School of Agricultural & SNP & Single-nucleotide polymorphism \\
\hline & and Life Sciences, University of Tokyo, Shizuoka, Japan & SSR & Simple-sequence repeats \\
\hline & Aquaculture Research Institute, Kindai University, & TW & Testes weight \\
\hline
\end{tabular}




\section{Introduction}

Recent advances in genomic tools have been proven to be very useful not only for ecological and evolutionary studies but also for the agricultural sciences. Notably, developments in various high-throughput cost-effective genotypingby-sequencing (GBS) systems, such as RADseq (and its derivatives) (Baird et al. 2008; Peterson et al. 2012; Andrews et al. 2016), MIGseq (Suyama and Matsuki 2015), and Ampliseq (Sato et al. 2019), facilitate a wide range of genetic analyses, including population structure analysis (Hohenlohe et al. 2010; Cavender-Bares et al. 2015; Hirase et al. 2020), linkage map construction (Elshire et al. 2011; Hoshino et al. 2016; Escudero et al. 2018), and forward genetics (Wilson et al. 2014; Zhou et al. 2015; Ieda et al. 2018; Kim et al. 2019), even for non-model organisms. These technologies are also recognized as powerful tools for aquaculture studies, as they are utilized in the implementation of selective breeding programs and the management of genetic diversity of target populations (Houston et al. 2012; Palaiokostas et al. 2013; Hosoya et al. 2018).

As an addition to these GBS tools, a new technology named Genotyping by Random Amplicon Sequencing, Direct, was developed recently (Hosoya et al. 2019). GRAS-Di is a non-targeted PCR-based GBS system, consisting of two sequential PCRs and a final purification step, as in the other non-targeted PCR base GBS system, namely multiplexed Inter-Simple Sequence Repeat (ISSR) genotyping by sequencing (MIG-seq, Suyama and Matsuki 2015). As variations of GBS, both GRAS-Di and MIG-seq have the advantage of reduced representation sequencing methods, and the cost, sample size, and the number of SNPs are optimally balanced. The major advantage of these methods is that they permit the use of small amounts of fragmented DNA $(<100 \mathrm{ng})$, unlike RADseq, which requires a large amount of high-quality DNA $(>1 \mu \mathrm{g}$; Etter et al. 2011; Hohenlohe et al. 2011). The main differences between GRAS-Di and MIG-seq are the first PCR primer. In the case of MIG-seq, the first PCR primers for MIGseq, including 12-bp SSR sequences with 2-bp anchor oligos at $3^{\prime}$ tail, are designed to amplify non-repetitive regions between SSRs. Therefore, only a limited number of SNPs can be genotyped because of the low frequency of SSRs over the genome (<1000; Watanabe et al. 2018). On the other hand, the first PCR primers of GRAS-Di consist of 10-bp Illumina Nextera adaptor plus 3-bp random oligomers at the 3 '-end, making it possible to amplify several thousands of loci even with such a simple library construction procedure, from various organisms. The availability for population structure analysis has been confirmed using mangrove fishes (Hosoya et al. 2019), alpine snow-bed herb (Ikeda et al. 2020), and Tsushima leopard cat (Ito et al. 2020). Because of its simplicity in library preparation and robustness against DNA degradation, it is expected that this technology will be applicable for a wide range of genetic studies in basic and applied sciences. However, the potential of GRAS-Di for genetic analysis is not yet fully investigated.

In this study, we tested the utility of GRAS-Di in aquaculture studies using the tiger pufferfish Takifugu rubripes. Known as Fugu, this fish has served as a model species for genomic studies since the first draft reference genome was published (Aparicio et al. 2002). A high-quality genomic reference (i.e., assembled at the chromosome level) is now available (Kai et al. 2011) and has been applied to various genetic studies (Kamiya et al. 2012; Hosoya et al. 2013; Ieda et al. 2018). The species is also known for the high market price and is recognized as one of the important aquaculture species in East Asia (Wang et al. 2016; Hamasaki et al. 2017). Although the fish itself is valuable, a particularly prized part of the fish in Japan is the testes. Testes size is a valuable economic trait, since mature testes, known as "shirako", are regarded as a delicacy in Japan (Hamasaki et al. 2013). Recently, a family line which is genetically precocious, i.e., early onset of testicular development about 2 months prior to the other lines, was identified (Yoshikawa et al. 2020). However, the genetic architecture of the precocious phenotype has not yet been studied.

The aim of this study is three-fold: (1) to test the utility of SNPs obtained by GRAS-Di for a family structure (parentage) analysis using a cultured population of the tiger pufferfish, (2) to evaluate the applicability of these SNPs for genetic map construction, and (3) to investigate the feasibility of the linkage map to dissect the genetic architecture of the precocious traits by means of quantitative trait locus (QTL) analysis. For this purpose, we raised four full-sib families, grand-offspring of a precocious male and a non-precocious female, and applied GRAS-Di on them.

\section{Materials and Methods}

\section{Experimental Crosses for Genetic Analysis}

We produced four full-sib families that were descendants of a grandfather (GF) and a grandmother (GM). The GF individual was derived from one of the major domesticated family lines in Japan and identified as genetically precocious by progeny tests (Yoshikawa et al. 2020), while GM belonged to another major line not characterized as precocious. These grandparents were crossed in March 2012 at private hatchery in Nagasaki Prefecture, Japan, to obtain the first generation $\left(F_{1}\right)$ (Table 1). $F_{1}$ individuals were raised at NPIF. Two males to be used as fathers (FA1 and FA2) and two females as 
Table 1 Relevant details of the parental fish used in this study

\begin{tabular}{|c|c|c|c|c|c|c|}
\hline \multirow[t]{2}{*}{ ID } & \multirow[t]{2}{*}{ Sex } & \multirow[t]{2}{*}{ Background } & \multicolumn{4}{|c|}{ Mating information } \\
\hline & & & Production & Date & Age (years) & $\mathrm{BW}^{\mathrm{a}}(\mathrm{kg})$ \\
\hline GF & Male & Genetically precocious sire & $F_{1}$ & 30-Mar-2012 & 2 & 1.8 \\
\hline GM & Female & $\begin{array}{l}\text { Derived from a major domesticated (non- } \\
\text { precocious) family line }\end{array}$ & & & 4 & 3.7 \\
\hline FA1 & Male & Selected randomly from $F_{1}$ individuals & $F_{2}$ & 7-Apr-2015 & 3 & 3.3 \\
\hline FA2 & Male & Same as above & & & 3 & 2.5 \\
\hline MO1 & Female & Same as above & & & 3 & 2.4 \\
\hline $\mathrm{MO} 2$ & Female & Same as above & & & 3 & 2.8 \\
\hline
\end{tabular}

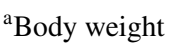

mothers (MO1 and MO2) were chosen randomly and crossed in a diallelic manner in April 2015 at NPIF to produce four full-sib families of the second generation $\left(F_{2}\right)$ (from Fam1 to Fam4, Table 2). The caudal fin was clipped from GF and the four parental fish. Unfortunately, a tissue sample for GM was not available from the commercial hatchery. These tissue samples were stored in $99.5 \%$ ethyl alcohol at $-30{ }^{\circ} \mathrm{C}$ for DNA extraction.

\section{Culture in Communal Tanks}

All test families were obtained by in vitro fertilization and reared following the recommendations of Yoshikawa et al. (2020). Each full-sib family of the $F_{2}$ generation was cultured separately until the mean standard length (SL) reached approximately $160 \mathrm{~mm}$ and mixed in a communal tank in September 2015. Before mixing, 120 individuals were randomly sampled from each full-sib family and each fish was fitted with a passive integrated transponder (PIT) tag (Bio Mark, ID, USA). Average SL and body weight (BW) at transfer to the communal tank are given in Table 2. In the communal tank, the fish were fed commercial pellets four to seven times a week until satiation. The holding tank was supplied with UV-sterilized ambient seawater. In December 2016, all the surviving fish were euthanized using an overdose

Table 2 Relevant details regarding the identity of the parents, number of fish transferred to the communal tank $(n)$, average standard length (SL), and body weight (BW) at tagging of each $F_{2}$ family

\begin{tabular}{llllll}
\hline Family ID & Sire & Dam & $n$ & SL $(\mathrm{cm})^{\mathrm{a}}$ & $\mathrm{BW}(\mathrm{g})^{\mathrm{a}}$ \\
\hline Fam1 & FA1 & MO1 & 120 & $16.4 \pm 1.1$ & $132.6 \pm 23.6$ \\
Fam2 & FA2 & MO1 & 120 & $16.3 \pm 1.0$ & $134.7 \pm 20.9$ \\
Fam3 & FA1 & MO2 & 120 & $17.0 \pm 0.8$ & $145.2 \pm 18.7$ \\
Fam4 & FA2 & MO2 & 120 & $16.0 \pm 1.1$ & $129.7 \pm 23.0$ \\
\hline
\end{tabular}

${ }^{a}$ Values are mean $\pm \mathrm{SD}$ of 2-phenoxyethanol (>600 ppm) (Fujifilm Wako Pure Chemical, Osaka, Japan). Survival rates of each family were in the range of 78.3 to $87.5 \%$. Each individual was visually sexed, and only males were used for the following analysis. SL and BW were measured, and the testes were excised and weighed. The gonadosomatic index $[\mathrm{GSI}=100 \times$ gonad weight $(\mathrm{g}) /$ total body weight (g)] was calculated for each male. The Spearman's rank order correlations were used to assess the strength of association among the four traits. The caudal fin was clipped from each specimen and stored in $99.5 \%$ ethyl alcohol at $-30{ }^{\circ} \mathrm{C}$ for DNA extraction.

\section{Genotyping}

Genomic DNA was extracted from the caudal fin using a DNeasy Blood and Tissue Kit (Qiagen, Hilden, Germany) according to the manufacturer's instructions. Library preparation and sequencing for GRAS-Di were done as described in Hosoya et al. (2019) by Eurofins Genomics Inc. (Tokyo, Japan). In short, template genomic DNA obtained from each sample was amplified with the first PCR primers including Illumina Nextera adaptor sequences and three-base random oligomers, followed by the second PCR using indexing primers consisting of the Illumina multiplexing dual index and P7/P5 adapter sequence. The final PCR products were pooled to produce two independent libraries ( $n=100$ and 98, respectively) and purified using the MiniElute PCR Purification Kit (Qiagen). These libraries were sequenced (one library per lane) on a HiSeq 2500 platform (Illumina, CA, USA), with 100 bp paired-end reads. The sequence data have been registered in the DDBJ Sequence Read Archive database (Accession No. DDBJ: DRA010711, Online resource 1).

To call genotypes, trimmed reads were mapped on to a Fugu reference genome assembly (FUGU5/fr3) (Kai et al. 2011). Trimming was done using Trimmomatic-0.36 (Bolger et al. 
2014) by setting the parameters as follows: ILLUMINACLIP NexteraPE-PE.fa:2:30:10, SLIDINGWINDOW:30:20, AVGQUAL:20, and MINLEN:80. Trimmed reads were mapped onto the reference using BWA-mem of BWA v 0.7.17 (Li 2013) with default parameters. Subsequently, mapped bam files were combined using Samtools v 1.9 (Li et al. 2009) and SNP calling was done by joint analysis using Freebayes v 1.3.1-17 (Garrison and Marth 2012, available at https://arxiv. org/abs/1207.3907) with options of --min-mapping-quality 10, --use-best-n-alleles 4 , and --min-alternate-fraction 0.2. We excluded insertion/deletion mutations and low-quality SNPs using vcftools v 1.17 (Danecek et al. 2011) with the following criteria, genotyped in $<80 \%$ of individuals, read quality $<20$, minor allele frequency $<0.01$, with more than two alleles, read depth $<5$, and average read depth $>500$.

\section{Genetic Analysis}

First, the population structure was inferred from the putative SNPs using principal component analysis (PCA) implemented in PLINK2.0 (Chang et al. 2015). Next, effective SNPs for which the allele inheritance (either from GF or GM) was known were extracted and a genetic linkage map for QTL analysis constructed. In this analysis, since it was not possible to obtain a tissue sample for GM from the commercial hatchery, the pattern of allele inheritance at many loci is ambiguous. However, the allelic state of the loci where GF's genotype was homozygous while those of the four parents (FA1, FA2, MO1, and MO2) were heterozygous could be determined even without GM's genomic information since the allele inherited from GF was known. Such SNP loci were considered effective in this study. Since these SNPs were available for all families, we were able to construct a single genetic map, with genetic distances between loci averaged over the four families. SNPs were further excluded based on the following criteria: (1) SNPs for which chromosomal position was unknown, (2) SNPs called in less than $98 \%$ of the individuals, and (3) SNPs that deviated from the Hardy-Weinberg equilibrium $\left(p<10^{-8}\right)$, except for those on chromosome 19. We note that Chr_19 is the sex chromosome of the tiger pufferfish (Kamiya et al. 2012), and thus, segregation of SNPs on this chromosome is expected to depart from Hardy-Weinberg equilibrium in this analysis because only males were used. Map distances between SNPs were calculated using Kosambi's map function implemented in R/qtl (Broman et al. 2003). When the map distance between two adjacent SNPs was larger than $50 \mathrm{cM}$, the downstream SNP was excluded because genotypes of these SNPs were possibly miscalled.

Genome-wide QTL analysis was done using the scanone function of R/qtl package by interval mapping (1 cM step) with the expectation-maximization (EM) algorithm. Although the family-based culture period was short (5 months) compared with the subsequent communal culture (15 months), there was the possibility of unexpected environmental effects from the familybased culture. The tank effect was included as an additive covariate in the model. Phenotypic values of SL, TW, and GSI, which were not distributed normally, were transformed to the corresponding normal quantiles using the nqrank function. The genome-wide thresholds for suggestive $\left(p<0.68=1-0.95^{22}\right)$ and significant $(p<0.05)$ QTLs were determined by means of 1,000 permutations. The suggestive threshold was adopted from Kirschner et al. (2012), considering that the tiger pufferfish has 22 pairs of chromosomes (Kai et al. 2011). The 95\% credible interval (CI) of the QTL was determined by the bayesint function. Phenotypic variation explained (PVE) (\%) by the QTL was estimated by means of a drop-oneterm analysis following multiple QTL model fitting via a Haley-Knott regression. Phenotype and genotype data for QTL analysis was listed in Online resource 1.

\section{Candidate Gene Search}

To identify candidate genes responsible for the phenotypes, we searched genes within the $95 \%$ CI of the significant QTL regions from the Fugu reference genome databases (Fugu5/ fr3) archived in UCSC Table Browser (https://genome.ucsc. edu, accessed May 25, 2020) and retrieved a list of Ensembl Genes. The biological function of each gene was checked using the NCBI Entrez Gene database (https://www.ncbi. nlm.nih.gov/gene, accessed June 7, 2020), and genes relating to maturation and growth, such as steroidogenic enzymes, gonadotropin releasing hormone, gonadotropin, and genes with cell proliferation and bone formation functions.

\section{Results}

\section{Phenotype Summary}

Sample number, average SL, BW, testes weight (TW), and GSI of male progeny are summarized in Table 3. BW was normally distributed (Shapiro-Wilk test, $p<0.05$ ), but SL, TW, and GSI were not. A significant correlation was observed between each pair of traits (Spearman's $p<0.05$ ) (Table 4).

\section{Genotyping}

In total, 24.2 million and 905.0 million reads were generated for the parental fish (GF, FA1, FA2, MO1, and MO2) and $193 F_{2}$ males by GRAS-Di, respectively. After 
Table 3 Number of samples (n), standard length (SL), body weight (BW), testes weight (TW), and gonadosomatic index (GSI) of the males in each $F_{2}$ family used for genetic map construction and quantitative trait loci analysis

\begin{tabular}{llllll}
\hline Family ID & $n$ & SL $(\mathrm{cm})^{\mathrm{a}}$ & $\mathrm{BW}(\mathrm{g})^{\mathrm{a}}$ & $\mathrm{TW}(\mathrm{g})^{\mathrm{a}}$ & $\mathrm{GSI}^{\mathrm{a}}$ \\
\hline Fam1 & 45 & $33.8 \pm 2.1$ & $1128.4 \pm 209.1$ & $51.3 \pm 43.2$ & $4.2 \pm 3.1$ \\
Fam2 & 50 & $33.2 \pm 1.8$ & $1071.4 \pm 166.5$ & $52.8 \pm 32.3$ & $4.7 \pm 2.5$ \\
Fam3 & 42 & $34.3 \pm 2.0$ & $1189.0 \pm 215.7$ & $46.3 \pm 33.5$ & $3.7 \pm 2.4$ \\
Fam4 & 56 & $32.8 \pm 2.5$ & $1056.3 \pm 231.5$ & $30.5 \pm 27.4$ & $2.6 \pm 2.0$ \\
\hline
\end{tabular}

${ }^{\mathrm{a}}$ Values are mean $\pm \mathrm{SD}$

trimming, $81.1 \%$ of the reads were retained on average. These trimmed reads were mapped onto the reference genome and applied for joint genotype calling. This yielded 633,818 variants. After filtering, 21,938 putative SNPs were retained.

\section{Family Structure Analysis}

These $22 \mathrm{~K}$ SNPs could detect the family structure successfully (Fig. 1). Individuals from each $F_{2}$ family clustered together and the four parents placed between the siblings, while GF plotted in the middle of the descendants. Parentage assignments based on the plot coincided perfectly with the family records based on PIT tag IDs.

\section{Linkage Map Construction}

A total of 2,491 effective SNPs were detected where the genotype of GF was homozygous and that of each of the parents (FA1, FA2, MO1, and MO2) was heterozygous. Subsequent filtration steps excluded 1,062 SNPs, with 434 SNPs excluded because the genomic positions of these SNPs could not be determined, 530 because of low genotyping rate $(<98 \%)$, and 98 deviated from the Hardy-Weinberg equilibrium $\left(p<10^{-8}\right)$. In total, 1,429 effective SNPs were obtained. Among these SNPs, six were excluded based on the map distance criterion (>50 cM between adjacent SNPs). Thus, the linkage map

Table 4 Pairwise correlation for standard length (SL), body weight (BW), testes weight (TW), and GSI. Spearman's correlation coefficients $(\rho)$ are shown in the lower half and $p$ values in the upper half of the matrix

\begin{tabular}{llccl}
\hline & SL & BW & TW & GSI \\
\hline SL & & $<0.0001$ & $<0.0001$ & $<0.0001$ \\
BW & 0.917 & & $<0.0001$ & $<0.0001$ \\
TW & 0.583 & 0.695 & & $<0.0001$ \\
GSI & 0.478 & 0.582 & 0.986 & \\
\hline
\end{tabular}

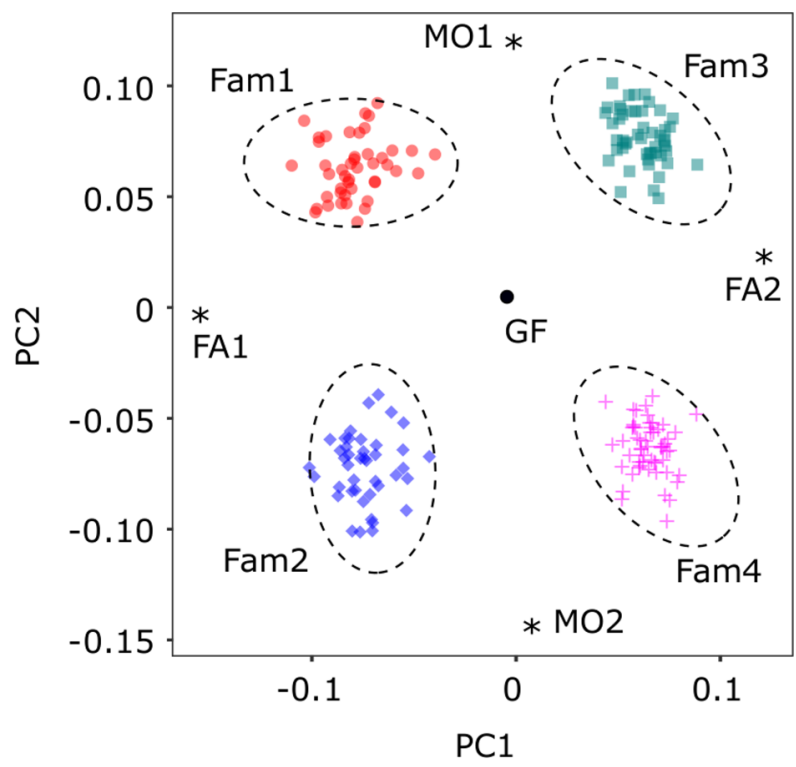

Fig. 1 Principal component analysis (PCA) plot for the genetic population structure of the test family, with the following individuals being represented: the grandfather (GF:•), $F_{1}$ parents (FA1, FA2, MO1, and MO2: $*$ ), and $F_{2}$ siblings from Fam1 $(\bullet)$, Fam2 $(\diamond)$, Fam3 $(\square)$, and Fam4 $(+)$. The dotted circle indicates each full-sib family tracked from PIT tag IDs

was constructed from the remaining 1423 SNPs (Fig. 2 and Online resource 2). The map spanned 1,949.2 cM, ranging from 46.3 (Chr_18) to $167.4 \mathrm{cM}$ (Chr_1), and the average intervals between SNPs were $1.75 \mathrm{cM}$ (with a maximum of 3.99 cM on Chr_9). The order of SNPs on the linkage map was in accordance with that on the reference genome.

\section{QTL Analysis}

The genome-wide significant levels $(p<0.05)$ of log of odds (LOD) score, determined by 1,000 times permutation test, were $3.82,3.98,4.02$, and 3.95 for SL, BW, TW, and GSI, respectively. Significant QTLs were detected for each trait (Fig. 3 and Table 5). The direction of additive and dominant effects of significant QTLs were consistent and alleles inherited from GM showed negative effects. Interestingly, body and testes size shared a QTL on Chr_14, where the 95\% CI of the QTL overlapped each other. The two body size traits (SL and BW) shared six QTLs, but the suggestive QTL $(p<0.68)$ on Chr_6 was only detected for BW. The effect of each QTL (i.e., PVE) was small even for the significant QLTs, as it ranged 5.4 to $10.5 \%$. TW and GSI shared all QTLs. LOD scores and PVE of the significant QTL were 5.1 and 5.9\% for TW and 4.3 and $4.8 \%$ for GSI, respectively. 


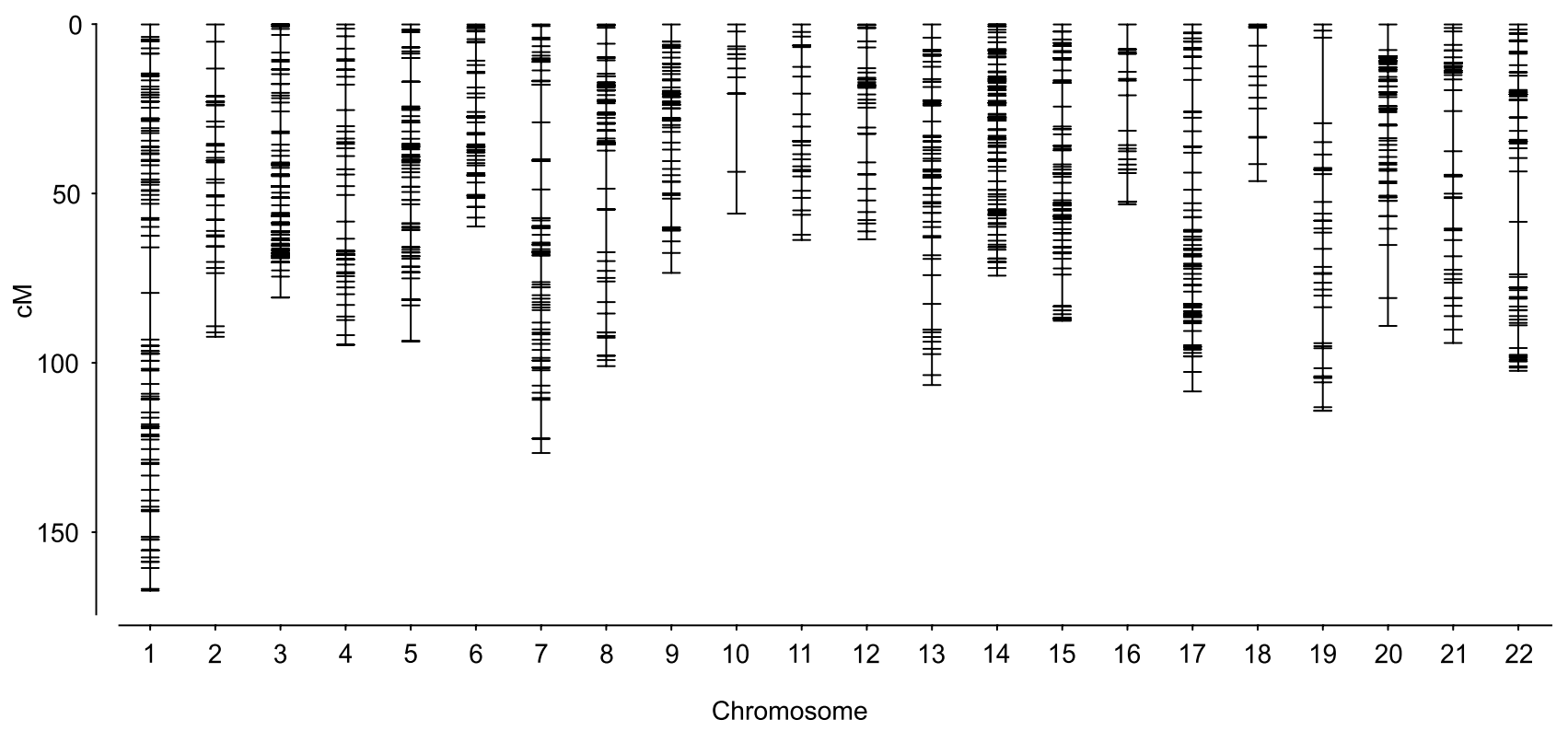

Fig. 2 The genetic linkage map constructed from the test cross of the tiger pufferfish (1,423 SNPs). Chromosomes are on the $x$-axis and genetic distance is shown on the $y$-axis

\section{Candidate Gene Search}

Maturation and/or body size related genes residing in the 95\% CI of the significant QTL on Chr_14 (13.9 cM to $40.0 \mathrm{cM}$, corresponding to 2.0 to $7.5 \mathrm{Mbp}$ ) and Chr_21 (0 $\mathrm{cM}$ to $13.7 \mathrm{cM}$, corresponding to 0.1 to $3.7 \mathrm{Mbp}$ ) were picked up from the Fugu genome assembly (FUGU5/fr3) (Table 6). All predicted protein-coding genes (Chr_14: 232 genes; Chr_21: 125 genes) are listed in Online resource 3. Among them, we listed the following genes as candidate genes underpinning the early onset of testis development and large body size seen in the precocious family line: fibroblast growth factor $18 \alpha(f g f l 8 a)$ and growth differentiation factor 9 ( $g d f 9$ ) on Chr_14 and bone morphogenetic factor 3 (bmp3) and fibroblast growth factor 5 (fgf5) on Chr_21.

\section{Discussion}

In this study, we investigated the utility of GRAS-Di for genetic studies, i.e., family structure analysis, genetic linkage map construction, and QTL analysis, using a cultured population of the tiger pufferfish. Approximately $22 \mathrm{~K}$ putative SNPs were obtained, which could resolve the fine-scale population structure and accurately assign parent-offspring pairs even for the very closely related families. A genetic linkage map was constructed using 1423 effective SNPs. The total length of the genetic map constructed from these effective SNPs was approximately
$1950 \mathrm{cM}$. This is equivalent to the map size previously constructed with 1,220 microsatellite markers $(2,200 \mathrm{cM})$ (Kai et al. 2011). Since a tissue sample from GM was not provided by the commercial hatchery, we could not fully utilize the polymorphisms between GF and GM, thus limiting the number of effective SNPs. The effective SNPs were also available for QTL mapping. As expected, individuals that inherited GF alleles at QTLs had larger testes. These results indicate that GRAS-Di is applicable for genetic analysis of aquaculture populations. Although SNP arrays are a much simpler and more reproducible genotyping platform than GBS (Robledo et al. 2018a), they require a large initial investment to design custom arrays from scratch and are currently available only for a limited number of aquatic species, such as Atlantic salmon (Salmo salar) (Houston et al. 2014; Yáñez et al. 2016; Bangera et al. 2017), common carp (Cyprinus carpio) (Xu et al. 2014), giant tiger shrimp (Penaeus monodon) (Baranski et al. 2014), catfish (Ictalurus punctatus and I. furcatus) (Liu et al. 2014; Zeng et al. 2017), Pacific oyster (Crassostrea gigas) (Qi et al. 2017; Gutierrez et al. 2018), European seabass (Dicentrarchus labrax) (Faggion et al. 2019), and Nile tilapia (Oreochromis niloticus) (Joshi et al. 2018; Peñaloza et al. 2020). Therefore, while GBS technologies are still the primary choice for populationscale genotyping in aquaculture species (Robledo et al. 2018a; Bresadola et al. 2020; Houston et al. 2020), GRAS-Di can be a viable and less expensive alternative choice for a genotyping platform. 

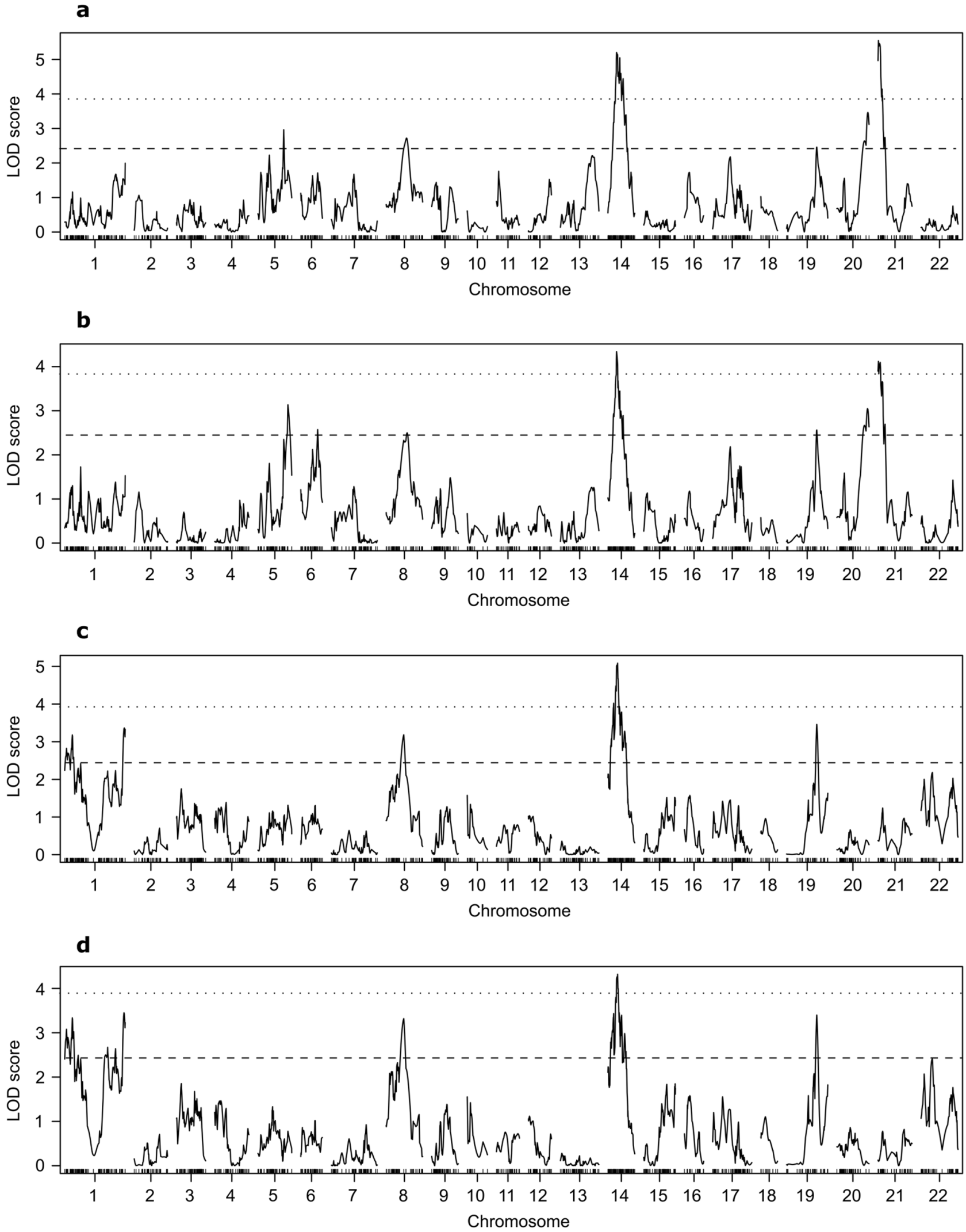

Fig. 3 Results of quantitative trait loci analysis of the tiger pufferfish for a standard length, $\mathbf{b}$ body weight, $\mathbf{c}$ testes weight, and $\mathbf{d}$ gonadosomatic index. Log of odds (LOD) scores are plotted over 22 chro- mosomes. Dotted and dashed horizontal lines indicate genome-wide significant $(p<0.05)$ and suggestive $(p<0.68)$ levels of LOD scores, respectively 
Table 5 Summary of quantitative trait loci (QTL) analysis for standard length (SL), body weight (BW), testes weight (TW), and gonadosomatic index (GSI)

\begin{tabular}{|c|c|c|c|c|c|c|c|c|c|}
\hline \multirow[t]{2}{*}{ Trait } & \multirow[t]{2}{*}{ Chromosome } & \multirow{2}{*}{$\begin{array}{l}\text { Position } \\
(\mathrm{cM})\end{array}$} & \multirow[t]{2}{*}{ SNP_ID ${ }^{a}$} & \multirow[t]{2}{*}{$\mathrm{LOD}^{\mathrm{b}}$} & \multicolumn{2}{|l|}{$95 \% \mathrm{CI}^{\mathrm{c}}$} & \multirow[t]{2}{*}{$\operatorname{PVE}^{\mathrm{d}}(\%)$} & \multirow[t]{2}{*}{$\operatorname{Add}^{\mathrm{e}}$} & \multirow[t]{2}{*}{$\operatorname{Dom}^{f}$} \\
\hline & & & & & Genetic map (cM) & Physical map (Mb) & & & \\
\hline \multirow[t]{6}{*}{ SL } & Chr_5 & 71.5 & Chr_5:10,219,766 & 2.96 & $2.3-93.5$ & $0.22-11.83$ & 5.02 & 0.55 & 0.77 \\
\hline & Chr_8 & 56.0 & Chr_8:10,920,029 & 2.72 & 31.4-97.9 & $8.95-13.61$ & 1.03 & -0.19 & 0.38 \\
\hline & Chr_14 & 23.9 & Chr_14:4,678,973 & 5.20 & 21.0-43.3 & 4.14-7.89 & 6.42 & -0.81 & -0.15 \\
\hline & Chr_19 & 83.6 & Chr_19:10,727,069 & 2.46 & $3.9-113.1$ & $0.32-13.67$ & 3.45 & -1.08 & 0.33 \\
\hline & Chr_20 & 86.0 & Chr_20:13,312,894 & 3.47 & $65.2-89.1$ & $10.94-13.31$ & 3.13 & 0.69 & 0.10 \\
\hline & Chr_21 & 1.0 & Chr_21:96,184 & 5.55 & $0.0-7.6$ & $0.05-0.75$ & 10.50 & -0.84 & -0.78 \\
\hline \multirow[t]{7}{*}{ BW } & Chr_5 & 83.1 & Chr_5:11,221,461 & 3.13 & $29.0-93.8$ & $3.79-12.00$ & 8.37 & 84.05 & 35.2 \\
\hline & Chr_6 & 46.7 & Chr_6:7,686,560 & 2.57 & $0.0-57.1$ & $0.26-8.50$ & 4.94 & 27.02 & -92.33 \\
\hline & Chr_8 & 58.0 & Chr_8:10,920,029 & 2.50 & $27.6-91.0$ & $8.48-12.97$ & 0.69 & -18.10 & 30.04 \\
\hline & Chr_14 & 23.9 & Chr_14:4,678,973 & 4.34 & $15.5-42.1$ & $2.44-7.88$ & 5.37 & -72.50 & -13.62 \\
\hline & Chr_19 & 83.6 & Chr_19:10,727,069 & 2.56 & $58.0-113.1$ & $6.20-13.67$ & 3.63 & -87.10 & 6.98 \\
\hline & Chr_20 & 85.0 & Chr_20:12,076,849 & 3.05 & $65.2-89.1$ & $10.94-13.31$ & 3.21 & 67.42 & 11.99 \\
\hline & Chr_21 & 1.0 & Chr_21:96,184 & 4.12 & $0.0-13.7$ & $0.05-3.70$ & 7.00 & -74.96 & -45.83 \\
\hline \multirow[t]{4}{*}{ TW } & Chr_1 & 165.0 & Chr_1:22,807,065 & 3.37 & $0.0-167.4$ & $0.17-22.90$ & 3.14 & -8.27 & 7.36 \\
\hline & Chr_8 & 48.6 & Chr_8:10,856,529 & 3.18 & $9.6-67.3$ & $5.01-11.33$ & 4.69 & -8.99 & -4.32 \\
\hline & Chr_14 & 26.7 & Chr_14:5,297,579 & 5.09 & 13.9-40.0 & $2.04-7.45$ & 5.90 & -12.16 & -3.38 \\
\hline & Chr_19 & 83.6 & Chr_19:10,727,069 & 3.46 & $71.7-114.2$ & $8.76-13.78$ & 5.67 & -30.87 & 20.92 \\
\hline \multirow[t]{4}{*}{ GSI } & Chr_1 & 164.0 & Chr_1:22,807,065 & 3.55 & $0.0-167.4$ & $0.17-22.90$ & 3.51 & -0.68 & 0.51 \\
\hline & Chr_8 & 48.6 & Chr_8:10,856,529 & 3.37 & $9.6-67.3$ & $5.01-11.33$ & 5.25 & -0.69 & -0.45 \\
\hline & Chr_14 & 26.7 & Chr_14:5,297,579 & 4.33 & $8.7-48.9$ & $1.30-7.97$ & 4.75 & -0.82 & -0.21 \\
\hline & Chr_19 & 83.6 & Chr_19:10,727,069 & 3.40 & $60.3-114.2$ & $6.47-13.78$ & 5.94 & -2.48 & 1.83 \\
\hline
\end{tabular}

Significant QTLs $(p<0.05)$ are highlighted with bold font

${ }^{\text {a }}$ ID of the SNP nearest the log of odds (LOD) peak position

${ }^{\mathrm{b}} \mathrm{LOD}$ score at peak position

${ }^{\mathrm{c}} 95 \%$ bayesian credible interval (CI)

${ }^{\mathrm{d}}$ Phenotypic variation explained (PVE)

${ }^{\mathrm{e}}$ Estimated additive effect from the grandmother alleles

${ }^{\mathrm{f}}$ Estimated dominance effect from the grandmother alleles

Upon searching for maturation/growth related genes among the 232 and 125 predicted protein-coding genes within the 95\% CI region of the two significant QTLs on Chr_14 and Chr_21, respectively, we found $g d f 9$ (for both maturation and growth) and $f g f 18 a, b m p 3$, and $f g f 5$ (for growth). Notably, GDF9, a member of the transforming growth factor beta (TGF $\beta$ ) superfamily, was first found as an oocyte-specific growth factor in vertebrates (McPherron and Lee 1993; McGrath et al. 1995) and is known as one of the control factors of steroid hormones: down-regulating estradiol and progesterone while up-regulating androgen (Solovyeva et al. 2000; Vitt et al. 2000; Spicer et al. 2006; Orisaka et al. 2009). In addition, GDF9 also acts on germ or somatic cells and controls spermatogenesis in vivo (He et al. 2012; Guo et al. 2013; Yan et al. 2020). In a previous study, we found that the precocious trait of the male tiger pufferfish was characterized by high levels of plasma estradiol$17 \beta$ (E2) prior to the initiation of testicular development (Yoshikawa et al. 2020). Thus, polymorphisms in $g d f 9$ (and/or its regulatory region) may have enhanced E2 synthesis, leading to the precocious maturation of the family line. The TGF $\beta$ superfamily (BMP3) and fibroblast growth factor family (FGF5 and FGF18a) are known growth-related genes that play important roles in a variety of biological processes including cell proliferation, embryonic development, and bone/cartilage formation (Clase et al. 2000; Daluiski et al. 2001; Haque et al. 2007). These genes may also be responsible for the large body size of the precocious family line.

A significant QTL shared between TW and BW was detected on Chr_14. This is consistent with the previous finding that these traits showed a positive phenotypic correlation in the precocious family line that GF belonged 
Table 6 Maturation- and growth-related genes located in the $95 \%$ credible interval of significant QTLs

\begin{tabular}{lll}
\hline Chromosome & Gene symbol & Gene name \\
\hline Chr_14 & $f g f 18 a$ & Fibroblast growth factor 18a \\
& $e g r 1$ & Early growth response 1 \\
& $g d f 9$ & Growth differentiation factor 9 \\
& $n s d h l$ & NAD(P) dependent steroid dehydrogenase-like \\
& zgc:194246 & (Predicted to be involved in spermatogenesis) \\
& aplnra & Apelin receptor a \\
& rflna & Refilin A \\
hmgcra & 3-Hydroxy-3-methylglutaryl-CoA reductase a \\
Chr_21 & Isl1 & ISL LIM homeobox 1 \\
& kazald3 & Kazal-type serine peptidase inhibitor domain 3 \\
& bmp3 & Bone morphogenetic protein 3 \\
& $f g f 5$ & Fibroblast growth factor 5 \\
& $b m p 2 k$ & BMP2 inducible kinase \\
\hline
\end{tabular}

to (Yoshikawa et al. 2020). These results suggest that the two traits have at least a partially common genetic architecture. Thus, it may be possible that both these genetic traits could be improved simultaneously. However, the genetic effect (i.e., PVE) of the significant QTL and other suggestive QTLs were small, and these values could even have been overestimated with the small number of samples, due to Beavis effect (Beavis 1994, 1998; Xu 2003). Therefore, the precociousness and the large body size seen in the elite family line seem to be polygenic and it would be difficult to directly integrate these QTLs into the selective breeding programs of the tiger pufferfish via marker-assisted selection. Instead, genomic selection (GS) is a better choice. GS is a selective breeding technology where genomic breeding values of selection candidates are predicted using linear regression linking genotypes and phenotypes of related individuals (Meuwissen et al. 2001). It has been integrated in some aquaculture species, including Atlantic salmon (Ødegård et al. 2014; Tsai et al. 2015; Robledo et al. 2018b), Yesso scallop (Patinopecten yessoensis) (Dou et al. 2016), Pacific oyster (Gutierrez et al. 2018), and coho salmon (Oncorhynchus kisutch) (Barría et al. 2018). Although hundreds of thousands of SNPs are required to conduct GS for livestock animals (Fan et al. 2010), it appears that a few thousand of SNPs are sufficient to gain high prediction accuracy in aquaculture species where cultured populations often consist of closely related individuals (Zenger et al. 2019; Kriaridou et al. 2020). At the population level, we were able to detect $22 \mathrm{~K}$ SNP loci using GRAS-Di in our rather small population, and therefore, we expect that GRAS-Di can be applied for GS of aquaculture species.

\section{Conclusion}

Our results demonstrate that GRAS-Di is a practical genotyping tool for genetic studies of the cultured tiger pufferfish, and therefore, presumably useful for other aquaculture species. We were able to detect accurate population structure and construct a fine-scale linkage map construction. Furthermore, we could dissect small effect QTLs for body size and maturation-related traits of the population, suggesting that the precociousness is polygenic, and GS is the better choice for a breeding strategy for this trait rather than marker-assisted selection.

Supplementary Information The online version contains supplementary material available at https://doi.org/10.1007/s10126-020-10013-4.

Acknowledgments We thank Dr. K. Miyaki from Nagasaki Prefectural Institute of Fisheries for valuable discussion and support during the study.

Authors' Contributions $\mathrm{SY}, \mathrm{KKi}$, and $\mathrm{SH}$ were responsible for the design of this study and drafting the manuscript. SY, MH, KKa, TY, and $\mathrm{HC}$ contributed by maintaining the fish and conducting the rearing experiments. SY and SH did genetic analysis. All authors read and approved the final manuscript.

Funding This work was supported by grants from the Project of the NARO Bio-oriented Technology Research Advancement Institution (Research program on development of innovative technology: 01017B).

Data Availability All raw sequencing data have been deposited in the DDBJ Sequence Read Archive database (Accession No. DDBJ: DRA010711).

\section{Compliance with Ethical Standards}

Conflict of Interest The authors declare that they have no conflict of interest. 
Ethics Approval All experiments were approved by the local Fish Care Committee of Nagasaki Prefectural Institute of Fisheries (NPIF) (\#NPIF-0001) and carried out in accordance with the Guidelines for Fish Experimentation in NPIF.

Open Access This article is licensed under a Creative Commons Attribution 4.0 International License, which permits use, sharing, adaptation, distribution and reproduction in any medium or format, as long as you give appropriate credit to the original author(s) and the source, provide a link to the Creative Commons licence, and indicate if changes were made. The images or other third party material in this article are included in the article's Creative Commons licence, unless indicated otherwise in a credit line to the material. If material is not included in the article's Creative Commons licence and your intended use is not permitted by statutory regulation or exceeds the permitted use, you will need to obtain permission directly from the copyright holder. To view a copy of this licence, visit http://creativecommons.org/licenses/by/4.0/.

\section{References}

Andrews KR, Good JM, Miller MR, Luikart G, Hohenlohe PA (2016) Harnessing the power of RADseq for ecological and evolutionary genomics. Nat Rev Genet 17:81-92

Aparicio S, Chapman J, Stupka E, Putnam N, Chia J, Dehal P, Christoffels A, Rash S, Hoon S, Smit A, Gelpke MDS, Roach J, Oh T, Ho IY, Wong M, Detter C, Verhoef F, Predki P, Tay A, Lucas S, Richardson P, Smith SF, Clark MS, Edwards YJK, Doggett N, Zharkikh A, Tavtigian SV, Pruss D, Barnstead M, Evans C, Baden H, Powell J, Glusman G, Rowen L, Hood L, Tan YH, Elgar G, Hawkins T, Venkatesh B, Rokhsar D, Brenner S (2002) Whole-genome shotgun assembly and analysis of the genome of Fugu rubripes. Science 297:1301-1310

Baird NA, Etter PD, Atwood TS, Currey MC, Shiver AL, Lewis ZA, Selker EU, Cresko WA, Johnson EA (2008) Rapid SNP discovery and genetic mapping using sequenced RAD markers. PLoS One 3:e3376

Bangera R, Correa K, Lhorente JP, Figueroa R, Yáñez JM (2017) Genomic predictions can accelerate selection for resistance against Piscirickettsia salmonis in Atlantic salmon (Salmo salar). BMC Genomics 18:121

Baranski M, Gopikrishna G, Robinson NA, Katneni VK, Shekhar MS, Shanmugakarthik J, Jothivel S, Gopal C, Ravichandran P, Kent M, Arnyasi M, Ponniah AG (2014) The development of a high density linkage map for black tiger shrimp (Penaeus monodon) based on cSNPs. PLoS One 9:e85413

Barría A, Christensen KA, Yoshida GM, Correa K, Jedlicki A, Lhorente JP, Davidson WS, Yáñez JM (2018) Genomic predictions and genome-wide association study of resistance against Piscirickettsia salmonis in coho salmon (Oncorhynchus kisutch) using ddRAD sequencing. G3 8:1183-1194

Beavis WD (1994) The power and deceit of QTL experiments: lessons from comparative QTL studies. Proceedings of the Forty-Ninth Annual Corn and Sorghum Industry Research Conference, ASTA, Washington DC 250-266

Beavis WD (1998) QTL analyses: power, precision, and accuracy. In: Paterson AH (ed) Molecular dissection of complex traits. CRC Press, New York, pp 145-162

Bolger AM, Lohse M, Usadel B (2014) Trimmomatic: a flexible trimmer for Illumina sequence data. Bioinformatics 30:2114-2120

Bresadola L, Link V, Buerkle CA, Lexer C, Wegmann D (2020) Estimating and accounting for genotyping errors in RAD-seq experiments. Mol Ecol Resour 20:856-870
Broman KW, Wu H, Sen Ś, Churchill GA (2003) R/qt1: QTL mapping in experimental crosses. Bioinformatics 19:889-890

Cavender-Bares J, González-Rodríguez A, Eaton DA, Hipp AA, Beulke A, Manos PS (2015) Phylogeny and biogeography of the American live oaks (Quercus subsection Virentes): a genomic and population genetics approach. Mole Ecol 24:3668-3687

Chang CC, Chow CC, Tellier LC, Vattikuti S, Purcell SM, Lee JJ (2015) Second-generation PLINK: rising to the challenge of larger and richer datasets. Gigascience 4:7

Clase KL, Mitchell PJ, Ward PJ, Dorman CM, Johnson SE, Hannon K (2000) FGF5 stimulates expansion of connective tissue fibroblasts and inhibits skeletal muscle development in the limb. Dev Dyn 219:368-380

Daluiski A, Engstrand T, Bahamonde ME, Gamer LW, Agius E, Stevenson SL, Cox K, Rosen V, Lyons KM (2001) Bone morphogenetic protein-3 is a negative regulator of bone density. Nat Genet 27:84-88

Danecek P, Auton A, Abecasis G, Albers CA, Banks E, DePristo MA, Handsaker RE, Lunter G, Marth GT, Sherry ST, McVean G, Durbin $\mathrm{R}$ (2011) The variant call format and VCFtools. Bioinformatics 27:2156-2158

Dou J, Li X, Fu Q, Jiao W, Li Y, Li T, Wang Y, Hu X, Wang S, Bao Z (2016) Evaluation of the 2b-RAD method for genomic selection in scallop breeding. Sci Rep 6:19244

Elshire RJ, Glaubitz JC, Sun Q, Poland JA, Kawamoto K, Buckler ES, Mitchell SE (2011) A robust, simple genotyping-by-sequencing (GBS) approach for high diversity species. PLoS One 6:e19379

Escudero M, Hahn M, Hipp AL (2018) RAD-seq linkage mapping and patterns of segregation distortion in sedges: meiosis as a driver of karyotypic evolution in organisms with holocentric chromosomes. J Evol Biol 31:833-843

Etter PD, Bassham S, Hohenlohe PA, Johnson EA, Cresko WA (2011) SNP discovery and genotyping for evolutionary genetics using RAD sequencing. Methods Mol Biol 772:157-178

Faggion S, Vandeputte M, Chatain B, Gagnaire PA, Allal F (2019) Population-specific variations of the genetic architecture of sex determination in wild European sea bass Dicentrarchus labrax L. Heredity 122:612-621

Fan B, Du ZQ, Gorbach DM, Rothschild MF (2010) Development and application of high-density SNP arrays in genomic studies of domestic animals. Asian-Australasian J Anim Sci 23:833-847

Garrison E, Marth G (2012) Haplotype-based variant detection from short-read sequencing. arXiv: 1207.3907 preprint

Guo QY, Gao ZZ, Zhao L, He JP, Dong CS (2013) Expression of growth differentiation factor 9 (GDF9), ALK5, and claudin-11 in adult alpaca testis. Acta Histochem 115:16-21

Gutierrez AP, Matika O, Bean TP, Houston RD (2018) Genomic selection for growth traits in Pacific oyster (Crassostrea gigas): potential of low-density marker panels for breeding value prediction. Front Genet 9:391

Hamasaki M, Takeuchi Y, Miyaki K, Yoshizaki G (2013) Gonadal development and fertility of triploid grass puffer Takifugu niphobles induced by cold shock treatment. Mar Biotechnol 15:133-144

Hamasaki M, Takeuchi Y, Yazawa R, Yoshikawa S, Kadomura K, Yamada T, Miyaki K, Kikuchi K, Yoshizaki G (2017) Production of tiger puffer Takifugu rubripes offspring from triploid grass puffer Takifugu niphobles parents. Mar Biotechnol 19:579-591

Haque T, Nakada S, Hamdy RC (2007) A review of FGF18: its expression, signaling pathways and possible functions during embryogenesis and post-natal development. Histol Histopathol 22:97-105

He Z, Wu Y, Xie J, Wang T, Zhang L, Zhang W (2012) Growth differentiation factor 9 (Gdf9) was localized in the female as well as male germ cells in a protogynous hermaphroditic teleost 
fish, ricefield eel Monopterus albus. Gen Comp Endocrinol 178:355-362

Hirase S, Tezuka A, Nagano AJ, Kikuchi K, Iwasaki W (2020) Genetic isolation by distance in the yellowfin goby populations revealed by RAD sequencing. Ichthyol Res 67:98-104

Hohenlohe PA, Bassham S, Etter PD, Stiffler N, Johnson EA, Cresko WA (2010) Population genomics of parallel adaptation in threespine stickleback using sequenced RAD tags. PLoS Genet 6:e1000862

Hohenlohe PA, Amish SJ, Catchen JM, Allendorf FW, Luikart G (2011) Next-generation RAD sequencing identifies thousands of SNPs for assessing hybridization between rainbow and westslope cutthroat trout. Mol Ecol Resour 11:117-122

Hoshino A, Jayakumar V, Nitasaka E, Toyoda A, Noguchi H, Itoh T, Shin T, Minakuchi Y, Koda Y, Nagano AJ, Yasugi M, Honjo MN, Kudoh H, Seki M, Kamiya A, Shiraki T, Carninci P, Asamizu E, Nishide H, Tanaka S, Park K, Morita Y, Yokoyama K, Uchiyama I, Tanaka Y, Tabata S, Shinozaki K, Hayashizaki Y, Kohara Y, Suzuki Y, Sugano S, Fujiyama A, Iida S, Sakakibara Y (2016) Genome sequence and analysis of the Japanese morning glory Ipomoea nil. Nat Commun 7:13295

Hosoya S, Kai W, Fujita M, Miyaki K, Suetake H, Suzuki Y, Kikuchi K (2013) The genetic architecture of growth rate in juvenile Takifugu species. Evolution 67:590-598

Hosoya S, Kikuchi K, Nagashima H, Onodera J, Sugimoto K, Satoh K, Matsuzaki K, Yasugi M, Nagano AJ, Kumagayi A, Ueda K, Kurokawa T (2018) Assessment of genetic diversity in Coho salmon (Oncorhynchus kisutch) populations with no family records using ddRAD-seq. BMC Res Notes 11:548

Hosoya S, Hirase S, Kikuchi K, Nanjo K, Nakamura Y, Kohno H, Sano M (2019) Random PCR-based genotyping by sequencing technology GRAS-Di (genotyping by random amplicon sequencing, direct) reveals genetic structure of mangrove fishes. Mol Ecol Resour 19:1153-1163

Houston RD, Davey JW, Bishop SC, Lowe NR, Mota-Velasco JC, Hamilton A, Guy DR, Tinch AE, Thomson ML, Blaxter ML, Gharbi K, Bron JE, Taggart JB (2012) Characterisation of QTLlinked and genome-wide restriction site-associated DNA (RAD) markers in farmed Atlantic salmon. BMC Genomics 13:244

Houston RD, Taggart JB, Cézard T, Bekaert M, Lowe NR, Downing A, Talbot R, Bishop SC, Archibald AL, Bron JE, Penman DJ, Davassi A, Brew F, Tinch AE, Gharbi K, Hamilton A (2014) Development and validation of a high density SNP genotyping array for Atlantic salmon (Salmo salar). BMC Genomics 15:90

Houston RD, Bean TP, Macqueen DJ, Gundappa MK, Jin YH, Jenkins TL, Selly SLC, Martin SAM, Stevens JR, Santos EM, Davie A, Robledo D (2020) Harnessing genomics to fast-track genetic improvement in aquaculture. Nat Rev Genet 21:389-409

Ieda R, Hosoya S, Tajima S, Atsumi K, Kamiya T, Nozawa A, Aoki Y, Tasumi S, Koyama T, Nakamura O, Suzuki Y, Kikuchi K (2018) Identification of the sex-determining locus in grass puffer (Takifugu niphobles) provides evidence for sex-chromosome turnover in a subset of Takifugu species. PLoS One 13:e0190635

Ikeda H, Yakubov V, Barkalov V, Sato K, Fujii N (2020) East Asian origin of the widespread alpine snow-bed herb, Primula cuneifolia (Primulaceae), in the northern Pacific region (in press). J Biogeogr

Ito H, Nakajima N, Onuma M, Murayama M (2020) Genetic diversity and genetic structure of the wild Tsushima leopard cat from genome-wide analysis. Animals 10:1375

Joshi R, Árnyasi M, Lien S, Gjøen HM, Alvarez AT, Kent M (2018) Development and validation of 58K SNP-array and high-density linkage map in Nile tilapia (O. niloticus). Front Genet 9:472

Kai W, Kikuchi K, Tohari S, Chew AK, Tay A, Fujiwara A, Hosoya S, Suetake H, Naruse K, Brenner S, Suzuki Y, Venkatesh B (2011) Integration of the genetic map and genome assembly of fugu facilitates insights into distinct features of genome evolution in teleosts and mammals. Genome Biol Evol 3:424-442

Kamiya T, Kai W, Tasumi S, Oka A, Matsunaga T, Mizuno N, Fujita M, Suetake H, Suzuki S, Hosoya S, Tohari S, Brenner S, Miyadai T, Venkatesh B, Suzuki Y, Kikuchi K (2012) A trans-species missense SNP in Amhr2 is associated with sex determination in the tiger Pufferfish, Takifugu rubripes (Fugu). PLoS Genet 8:e1002798

Kim DI, Kai W, Hosoya S, Sato M, Nozawa A, Kuroyanagi M, Jo Y, Tasumi S, Suetake H, Suzuki Y, Kikuchi K (2019) The genetic basis of scale-loss phenotype in the rapid radiation of Takifugu fishes. Genes 10:1027

Kirschner J, Weber D, Neuschl C, Franke A, Böttger M, Zielke L, Powalsky E, Groth M, Shagin D, Petzold A, Hartmann N, Englert C, Brockmann GA, Platzer M, Cellerino A, Reichwald K (2012) Mapping of quantitative trait loci controlling lifespan in the shortlived fish Nothobranchius furzeri- a new vertebrate model for age research. Aging Cell 11:252-261

Kriaridou C, Tsairidou S, Houston RD, Robledo D (2020) Genomic prediction using low density marker panels in aquaculture: performance across species, traits, and genotyping platforms. Front Genet 11:124

Li H, Handsaker B, Wysoker A, Fennell T, Ruan J, Homer N, Marth G, Abecasis G, Durbin R (2009) The sequence alignment/map format and SAMtools. Bioinformatics 25:2078-2079

Li H (2013) Aligning sequence reads, clone sequences and assembly contigs with BWA-MEM. arXiv 1303:3997

Liu S, Sun L, Li Y, Sun F, Jiang Y, Zhang Y, Zhang J, Feng J, Kaltenboeck L, Kucuktas H, Liu Z (2014) Development of the catfish 250K SNP array for genome-wide association studies. BMC Res Notes 7:135

McGrath SA, Esquela AF, Lee SJ (1995) Oocyte-specific expression of growth/differentiation factor-9. Mol Endocrinol 9:131-136

McPherron AC, Lee SJ (1993) GDF-3 and GDF-9: two new members of the transforming growth factor- $\beta$ superfamily containing a novel pattern of cysteines. J Biol Chem 268:3444-3449

Meuwissen THE, Hayes BJ, Goddard ME (2001) Prediction of total genetic value using genome-wide dense marker maps. Genetics 157:1819-1829

Ødegård J, Moen T, Santi N, Korsvoll SA, Kjøglum S, Meuwisse THE (2014) Genomic prediction in an admixed population of Atlantic salmon (Salmo salar). Front Genet 5:402

Orisaka M, Jiang JY, Orisaka S, Kotsuji F, Tsang BK (2009) Growth differentiation factor 9 promotes rat preantral follicle growth by up-regulating follicular androgen biosynthesis. Endocrinology 150:2740-2748

Palaiokostas C, Bekaert M, Khan MGQ, Taggart JB, Gharbi K, McAndrew BJ, Penman DJ (2013) Mapping and validation of the major sex-determining region in Nile tilapia (Oreochromis niloticus L.) using RAD sequencing. PLoS One 8:e68389

Peterson BK, Weber JN, Kay EH, Fisher HS, Hoekstra HE (2012) Double digest RADseq: an inexpensive method for de novo SNP discovery and genotyping in model and non-model species. PLoS One 7:e37135

Peñaloza C, Robledo D, Barría A, Trịnh TQ, Mahmuddin M, Wiener P, Benzie JAH, Houston RD (2020) Development and validation of an open access SNP array for Nile tilapia (Oreochromis niloticus). G3 10:2777-2785

Qi H, Song K, Li C, Wang W, Li B, Li L, Zhang G (2017) Construction and evaluation of a high-density SNP array for the Pacific oyster (Crassostrea gigas). PLoS One 12:e174007

Robledo D, Palaiokostas C, Bargelloni L, Martínez P, Houston R (2018) Applications of genotyping by sequencing in aquaculture breeding and genetics. Rev Aquac 10:670-682 
Robledo D, Matika O, Hamilton A, Houston RD (2018b) Genome-wide association and genomic selection for resistance to amoebic gill disease in Atlantic salmon. G3 8:1195-1203

Sato M, Hosoya S, Yoshikawa S, Ohki S, Kobayashi Y, Itou T, Kikuchi K (2019) A highly flexible and repeatable genotyping method for aquaculture studies based on target amplicon sequencing using next-generation sequencing technology. Sci Rep 9:6904

Solovyeva EV, Hayashi M, Margi K, Barkats C, Klein C, Amsterdam A, Hsueh AJW, Tsafriri A (2000) Growth differentiation factor-9 stimulates rat theca-interstitial cell androgen biosynthesis. Biol Reprod 63:1214-1218

Spicer LJ, Aad PY, Allen D, Mazerbourg S, Hsueh AJ (2006) Growth differentiation factor-9 has divergent effects on proliferation and steroidogenesis of bovine granulosa cells. J Endocrinol 189:329-339

Suyama Y, Matsuki Y (2015) MIG-seq: an effective PCR-based method for genome-wide single-nucleotide polymorphism genotyping using the next-generation sequencing platform. Sci Rep 5:16963

Tsai HY, Hamilton A, Tinch AE, Guy DR, Gharbi K, Stear MJ, Matika O, Bishop SC, Houston RD (2015) Genome wide association and genomic prediction for growth traits in juvenile farmed Atlantic salmon using a high density SNP array. BMC Genomics 16:969

Vitt UA, Hayashi M, Klein C, Hsueh AJW (2000) Growth differentiation factor-9 stimulates proliferation but suppresses the follicle-stimulating hormone-induced differentiation of cultured granulosa cells from small antral and preovulatory rat follicles. Biol Reprod 62:370-377

Wang QL, Zhang HT, Ren YQ, Zhou Q (2016) Comparison of growth parameters of tiger puffer Takifugu rubripes from two culture systems in China. Aquaculture 453:49-53

Watanabe Y, Kawamata I, Matsuki Y, Suyama Y, Uehara K, Ito M (2018) Phylogeographic analysis suggests two origins for the riparian azalea Rhododendron indicum (L.) Sweet. Heredity 121:594-604

Wilson CA, High SK, McCluskey BM, Amores A, Yan YL, Titus TA, Anderson JL, Batzel P, Carvan MJ, Schartl M, Postlethwait JH (2014) Wild sex in zebrafish: loss of the natural sex determinant in domesticated strains. Genetics 198:1291-1308

Xu P, Zhang X, Wang X, Li J, Liu G, Kuang Y, Xu J, Zheng X, Ren L, Wang G, Zhang Y, Huo L, Zhao Z, Cao D, Lu C, Li C, Zhou Y, Liu
Z, Fan Z, Shan G, Li X, Wu S, Song L, Hou G, Jiang Y, Jeney Z, Yu D, Wang L, Shao C, Song L, Sun J, Ji P, Wang J, Li Q, Xu L, Sun F, Feng J, Wang C, Wang S, Wang B, Li Y, Zhu Y, Xue W, Zhao L, Wang J, Gu Y, Lv W, Wu K, Xiao J, Wu J, Zhang Z, Yu J, Sun X (2014) Genome sequence and genetic diversity of the common carp, Cyprinus carpio. Nat Genet 46:1212-1219

$\mathrm{Xu} \mathrm{S} \mathrm{(2003)} \mathrm{Theoretical} \mathrm{basis} \mathrm{of} \mathrm{the} \mathrm{Beavis} \mathrm{effect.} \mathrm{Genetics}$ 165:2259-2268

Yoshikawa S, Chuda H, Hamasaki M, Kadomura K, Yamada T, Kikuchi K, Hosoya S (2020) Precocious maturation in male tiger pufferfish Takifugu rubripes: genetics and endocrinology. Fish Sci 86:339-351

Yan T, Zhang S, Zhang Q, Deng F, Cai Y, He J, Ma Z, He L, Luo J, Yang D, He Z (2020) Expression patterns and oestradiol regulation of growth differentiation factor 9 in Schizothorax prenanti. Comp Biochem Physiol Part B 248-249:110470

Yáñez JM, Naswa S, López ME, Bassini L, Correa K, Gilbey J, Bernatchez L, Norris A, Neira R, Lhorente JP, Schnable PS, Newman S, Mileham A, Deeb N, Genova AD, Maass A (2016) Genomewide single nucleotide polymorphism discovery in Atlantic salmon (Salmo salar): validation in wild and farmed American and European populations. Mol Ecol Resour 16:1002-1011

Zeng Q, Fu Q, Li Y, Waldbieser G, Bosworth B, Liu S, Yang Y, Bao L, Yuan Z, Li N, Liu Z (2017) Development of a 690 K SNP array in catfish and its application for genetic mapping and validation of the reference genome sequence. Sci Rep 7:40347

Zenger KR, Khatkar MS, Jones DB, Khalilisamani N, Jerry DR, Raadsma HW (2019) Genomic selection in aquaculture: application, limitations and opportunities with special reference to marine shrimp and pearl oysters. Front Genet 9:693

Zhou L, Wang SB, Jian J, Geng QC, Wen J, Song Q, Wu Z, Li GJ, Liu YQ, Dunwell JM, Zhang J, Feng JY, Niu Y, Zhang L, Ren WL, Zhang YM (2015) Identification of domestication-related loci associated with flowering time and seed size in soybean with the RAD-seq genotyping method. Sci Rep 5:9350

Publisher's Note Springer Nature remains neutral with regard to jurisdictional claims in published maps and institutional affiliations. 